\title{
Decline of semen quality among 10932 males consulting for couple infertility over a 20-year period in Marseille, France
}

\author{
Cendrine Geoffroy-Siraudin ${ }^{1,2}$, Anderson Dieudonné Loundou ${ }^{3}$, Fanny Romain ${ }^{4}$, Vincent Achard ${ }^{1}$, \\ Blandine Courbière $^{2,5}$, Marie-Hélène Perrard ${ }^{6}$, Philippe Durand ${ }^{6}$ and Marie-Roberte Guichaoua ${ }^{1,2}$
}

Semen from 10932 male partners of infertile couples was analysed and sperm parameter trends were evaluated at the Reproduction Biology Laboratory of the University Hospital of Marseille (France) between 1988 and 2007. After 3-6 days of abstinence, semen samples were collected. Measurements of seminal fluid volume, $\mathrm{pH}$, sperm concentration, total sperm count, motility and detailed morphology of spermatozoa were performed. Sperm parameters were analysed on the entire population and in men with normal total numeration ( $\geqslant 40$ million per ejaculate). The whole population demonstrated declining trends in sperm concentration $(1.5 \%$ per year), total sperm count ( $1.6 \%$ per year), total motility ( $0.4 \%$ per year), rapid motility ( $5.5 \%$ per year) and normal morphology $(2.2 \%$ per year). In the group of selected samples with total normal sperm count, the same trends of sperm quality deterioration with time were observed. Our results clearly indicate that the quality of semen decreased in this population over the study period.

Asian Journal of Andrology (2012) 14, 584-590; doi:10.1038/aja.2011.173; published online 23 April 2012

Keywords: environment; male infertility; regional differences; semen quality; sperm parameters

\section{INTRODUCTION}

Numerous studies suggest a decline in semen quality in some parts of the world. ${ }^{1-8}$ By contrast, other studies have shown no evidence of deteriorating semen quality. ${ }^{9-16}$ Some studies concern infertile couples, while others analyse normal sperm parameters. Thus, a worldwide decreasing trend in semen parameter values can be neither confirmed nor rejected. ${ }^{17}$ It was recently reported that fecundity is affected by this decrease. ${ }^{18,19}$ It was speculated that decreasing sperm parameters are in response to adverse environmental factors. Nevertheless, the observed discrepancies between studies suggest regional differences in semen quality. ${ }^{20-22}$ Variations in environmental factors, industrial pollution and/or lifestyle could explain these discrepancies. A large number of environmental factors can pollute air, drinking water and food. This can directly alter the male gonad by blood-testis barrier disruption and cellular toxicity, or disrupt androgen biosynthesis and action. Among these environmental factors, oestrogenic or anti-androgenic endocrine disrupting compounds inhibit critical cellular process controlling steroidogenesis in Leydig cells and androgen binding to the androgen receptor. ${ }^{23}$ It has been hypothesized that endocrine disrupting compounds play a major role in the aetiology of increased incidence of testicular dysgenesis syndrome which gathers decreased quality of semen, cryptorchidism, hypospadias and testicular cancer. ${ }^{24}$ Chemicals with hormone-like activity can also disrupt programming of endocrine signalling pathways during development. Indeed, androgen and oestrogen receptors, which play critical but distinct roles in the physiology of sperm cells, are present on male germ cells. ${ }^{25-27}$

Owing to regional differences in semen quality, laboratories must conduct their own local studies over certain periods of time. ${ }^{28}$ This study's objective was to analyse sperm parameters in 10932 male population as well as a selected sample with a total normal sperm count over a period of 20 years, from 1988 to 2007. Since its opening, our laboratory has specialized in semen analysis and has been focused on spermatozoa research. To this end, we have performed a very precise, age-adjusted study of semen parameters obtained from the first semen analysis. These results were then computerized and are now presented, for the first time, in a detailed analysis of the spermatozoa's morphology over a course of time.

\section{MATERIALS AND METHODS}

Subjects

Patients in the Reproduction Biology Laboratory of the University Hospital are from Marseille (France) and its region. This area, with its maritime, automobile and petrochemical activities, constitutes one of the most heavily industrialized and most polluted regions in France (Study Aphekom, http://www.aphekom.org/).

\footnotetext{
${ }^{1}$ Reproduction Biology Laboratory, Conception Hospital, AP-HM, Marseille 13005, France; ${ }^{2}$ Aix-Marseille University, UMR CNRS IMBE 7263, Faculty of medicine of Marseille, Marseille 13005, France; ${ }^{3}$ Department of medical information, Conception Hospital, AP-HM, Marseille, 147 Bd Baille, Marseille 13005, France; ${ }^{4}$ Health Laboratory, Faculty of Medicine of Marseille, Marseille 13005, France; ${ }^{5}$ Centre of Assisted Reproductive Technique (CPMA), Conception Hospital, AP-HM, Marseille 13005, France and ${ }^{6}$ Functional Genomic Institute of Lyon, CNRS, INRA, ENS of Lyon, Lyon 69007, France

Correspondence: Dr MR Guichaoua (mguichaoua@ap-hm.fr)
}

Received: 14 September 2011; Revised: 19 October 2011; Accepted: 14 November 2011; Published online: 23 April 2012 
A semen evaluation for all subjects was routinely performed during the infertility work-up. Approval for this study was obtained from the French institutional review board, the CNIL (National Board of Data Processing and Liberties $n^{0}$ 909493) Statistical analyses were performed on the first sperm sample for each patient. We also performed statistical analyses on selected samples having a total normal sperm count ( $\geqslant 40$ million/ejaculate) according to the results obtained by Mukhopdayay et al. ${ }^{8}$ and Spirada et al. ${ }^{6}$ This corresponded to 7899 semen samples.

\section{Semen collection and quality control}

All semen samples were obtained by masturbation at our laboratory and ejaculated into a sterile plastic cup. Specimens were obtained after 3-6 days of sexual abstinence. This parameter is in accordance with the World Health Organization's (WHO) recommendation of $48 \mathrm{~h}$ to 7 days of sexual abstinence. ${ }^{29,30}$ The semen was incubated for $30 \mathrm{~min}$ at $37^{\circ} \mathrm{C}$ for liquefaction. Samples were analysed within 30-60 min after collection.

During the entirety of the study, four technicians, all having the same training, worked in the laboratory. One worked for 20 years, another for 10 years and two for 2 years each. The methods of analysis did not change widely during the course of the 20 years. The medical director of the laboratory remained the same for the study's entire 20 years. A new laminar flow hood with vertical flux and a second microscope for morphological analysis were introduced during this period. Technicians and medical doctors adhered to strict quality control (Prospective Biology, Continuous Vocational Training $\mathrm{n}^{0} 4154$ 00025 54).

\section{Semen analysis}

Analysis of volume, $\mathrm{pH}$, sperm concentration, total sperm count, percentages of motility, viability and morphology of spermatozoa were performed. Ejaculate volume was measured with graduated pipettes and $\mathrm{pH}$ was measured with $\mathrm{pH}$ paper. Sperm concentration and motility were evaluated using manual methods. Sperm concentration, after an appropriate dilution, was assessed by a haemocytometer. Since 1980, this procedure has been continually recommended by WHO. Spermatozoa motility was investigated with a Leica phasecontrast microscope (Leica Microsystems Wetzlar GmbH, Wetzlar, Germany) fitted with a $\times 40$ objective. Because motility was differently graded after 1996, this study has only considered sperm showing evidence of movements, 'total motility' (WHO grades $\mathrm{a}+\mathrm{b}+\mathrm{c}),{ }^{29}$ and the 'rapid progressive motility' (grade a) which did not change over the study. Viability was evaluated using the eosin-nigrosin staining method.

After haematoxylin/Shorr staining, sperm morphology was evaluated at a magnification of $\times 1000$ and in accordance with the classification described by David et al. ${ }^{31}$ This is the same classification modified by Auger and Eustache, ${ }^{32}$ which our laboratory has applied since 2003. By reason of modifications in this classification, the evolution of 'normal sperm morphology' and of 'bent tail' is presented until the end of 2002. For the neck, midpiece and tail, the abnormalities described by Auger and Eustache, ${ }^{32}$ 'asymetrical insertion', 'thin midpiece' and 'irregular tail' did not appear in the David classification. The other abnormalities were studied over the 20 years of the study. For the spermatozoon head, 'amorphous head' in David's classification was split into 'irregular acrosome' and 'irregular post-acrosomal region' in the Auger and Eustache classification. Thus, we were able to show the amorphous head trend over the study period. Leucocytes and immature germ cells were identified on morphological criteria after
haematoxylin/Shorr staining. In this study, we took account for the neutrophil polynuclear leukocytes, spermatocytes and spermatids, which are easily recognizable in a semen smear stained by haematoxylin/Shorr, with a few exceptions. ${ }^{29,30}$

\section{Statistical analyses}

Statistical analyses were performed using PASW Statistics version 17.0.2 (SPSS Inc., Chicago, IL, USA). Continuous variables are expressed as means \pm s.d. or as median with interquartile range (according to their distribution). Categorical variables are reported as count and percentages. Linear regression was used to examine trends over time in the semen characteristics. Since age influences the characteristics of semen, multiple linear regression models were used to assess the effect of age and calendar year on semen characteristics. The residuals of the fitted linear models were then utilized as the age-adjusted data. Multiple coefficient of determination $\left(R^{2}\right)$ is presented for each model along with $P$ value. All the tests were two-sided. The statistical significance was defined as $P<0.05$.

\section{RESULTS}

\section{Total semen samples}

The mean age of the studied population was $35.1 \pm 0.9$ years. Overtime, the mean age increased significantly from $34.2 \pm 5.8$ years in 1988 to $36.5 \pm 5.3$ years in $2007\left(R^{2}=0.837, P<0.001\right)$. Only age-adjusted results are presented.

Neither the seminal fluid volume $(3.5 \pm 1.8 \mathrm{ml})$ nor the sperm viability $(65.7 \% \pm 23.2 \%)$ varied over the study period. These two parameters were in the range of the normal values of the WHO guidelines. ${ }^{29,30}$ The $\mathrm{pH}$ increased over the study period $\left(R^{2}=0.719\right.$, $P<0.001$; Figure 1a).

Decreases in mean sperm concentration and mean total sperm count were observed over the study period (from 74.1 to 57.1 million $\mathrm{ml}^{-1}$, $R^{2}=0.972, P<0.001$ and from 232.0 to 166.4 million, $R^{2}=0.860$, $P<0.001$, respectively). Nevertheless, the mean values of these two parameters were always above the normal range. The medians varied from 50.4 to 35.4 million $\mathrm{ml}^{-1}$ for sperm concentration, and from 120.5 to 100.8 million for total sperm count. Hence, these two parameters decreased by $1.5 \%$ and $1.6 \%$ per year, respectively (Figure $\mathbf{1 b}$ and c, Table 1).

The proportion of men with a normal sperm count decreased from $75.0 \%$ to $69.1 \%$, with a decrease rate of $0.4 \%(P=0.013)$. By contrast, men presenting with a severe oligozoospermia ( $\leqslant 5$ million $\mathrm{ml}^{-1}$ ) increased by $4 \%(P=0.002)$. Azoospermia affected patients increased by $1.2 \%$, from $3.26 \%$ to $5.30 \%$. This increase was not deemed significant.

The mean percentage of total motile spermatozoa (grades $\mathrm{a}+\mathrm{b}+\mathrm{c}$ ) declined from 1988 to 2007 (from 56.5\% to 52.4\%, $R^{2}=0.329$, $P=0.008$ ). The rapid progressive motility (grade a) decreased over the study period from $26.4 \%$ to $8.5 \% \quad\left(R^{2}=0.848, \quad P<0.001\right)$ (Figure 1d and e, Table 1).

The percentage of spermatozoa with normal morphology declined between 1988 and 2002 from $43.1 \%$ to $34.8 \%$. It exhibited a negative correlation with time $\left(R^{2}=0.764, P<0.001\right)$ with a decrease rate of $2.2 \%$ per year (Figure 1f, Table 1). Detailed analysis of the morphological characteristics of spermatozoa showed increases of abnormalities of the three regions of the spermatozoa: head, neck and tail (for details, see Figure 2). The mean number of immature germ cells (spermatocytes I and II, and spermatids) increased from $2.1 \%$ to $8.5 \%\left(R^{2}=0.206, P<0.05\right)$ and neutrophil leucocytes increased from $0.6 \%$ to $7.9 \%\left(R^{2}=0.717, P<0.01\right)$. 

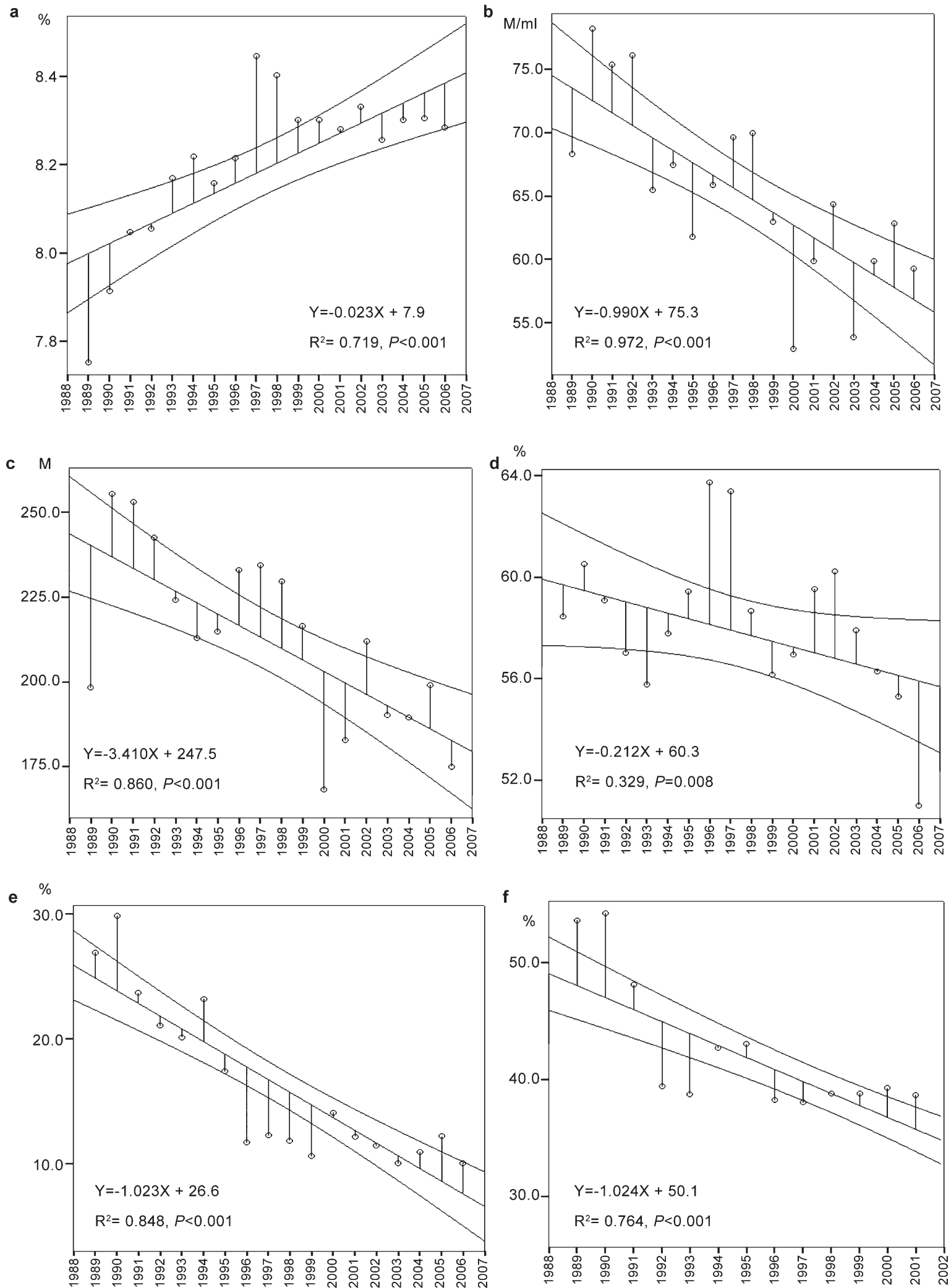

Figure 1 Linear regression lines of the means per year of the main sperm parameters. For each parameter, the graph shows the linear regression line with $95 \%$ confidence interval over the study period. The pH increases significantly with time (a). Significant decreases in mean sperm concentration (b), mean total sperm count per ejaculate (c), total motility (d), rapid motility (e) and normal morphology (f) were observed. For the morphology, results are showed until the end of 2002 , because some modifications in morphological analysis were introduced from 2003. M, million. 
Table 1 Semen characteristics of the first sample of 10932 men consulting for couple infertility between 1988 and 2007

\begin{tabular}{|c|c|c|c|c|c|c|}
\hline \multirow[t]{2}{*}{ Year } & \multirow[t]{2}{*}{ Number of samples } & \multirow{2}{*}{$\begin{array}{c}\text { Sperm concentration }(\mathrm{M} / \mathrm{ml}) \\
\text { Median (IQR 25-75) }\end{array}$} & \multirow{2}{*}{$\frac{\text { Total sperm count (M/ej) }}{\text { Median (IQR 25-75) }}$} & \multirow{2}{*}{ 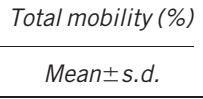 } & \multirow{2}{*}{$\frac{\text { Rapid motility (\%) }}{\text { Median (IQR 25-75) }}$} & \multirow{2}{*}{ 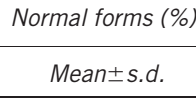 } \\
\hline & & & & & & \\
\hline 1988 & 92 & $50.4(11.3-102.7)$ & $120.5(39.1-342.6)$ & $56.5 \pm 19.2$ & $20(0-50)$ & $43.1 \pm 19.8$ \\
\hline 1989 & 243 & $42.4(12.2-89.2)$ & 144.2 (32.9-274.4) & $58.5 \pm 18.9$ & $30(10-40)$ & $53.6 \pm 17.1$ \\
\hline 1990 & 339 & $47.4(14-110)$ & $161.7(42.2-358.6)$ & $60.5 \pm 16.8$ & $30(20-40)$ & $54.2 \pm 15.9$ \\
\hline 1991 & 357 & $52.8(11.6-114.7)$ & 172.5 (32.4-385.7) & $59.1 \pm 16.1$ & $20(10-40)$ & $48.1 \pm 17.5$ \\
\hline 1992 & 360 & 46.1 (13.1-104.7) & 150.5 (37.5-311.0) & $57.0 \pm 17.9$ & $20(10-30)$ & $39.4 \pm 17.1$ \\
\hline 1993 & 384 & $38.2(8.9-90.4)$ & 130.9 (29.9-303.8) & $55.7 \pm 15.7$ & $20(10-30)$ & $38.8 \pm 17.2$ \\
\hline 1994 & 552 & $44.1(12.5-93)$ & 138.7 (37.9-300.0) & $57.8 \pm 15.3$ & $20(10-30)$ & $42.7 \pm 18.5$ \\
\hline 1995 & 526 & $36(7.4-86.4)$ & $120.8(28.4-302.4)$ & $59.5 \pm 16.3$ & $10(5-30)$ & $43.0 \pm 17.8$ \\
\hline 1996 & 456 & $43(11.2-91.4)$ & $136.3(34.8-310.5)$ & $63.7 \pm 16.7$ & $10(0-20)$ & $38.2 \pm 17.1$ \\
\hline 1997 & 772 & 44.9 (14.1-98.7) & $139.8(43.6-326.1)$ & $63.4 \pm 16.9$ & $10(5-20)$ & $38.0 \pm 15.8$ \\
\hline 1998 & 743 & $46.4(12.6-102.8)$ & $145.3(40.0-330.4)$ & $58.7 \pm 17.1$ & $10(0-20)$ & $38.8 \pm 17.1$ \\
\hline 1999 & 701 & $38.4(8.4-87.9)$ & 135.5 (26.2-296.9) & $56.2 \pm 17.9$ & $10(0-20)$ & $38.8 \pm 17.7$ \\
\hline 2000 & 728 & 31.7 (9.7-77.4) & $99.2(27.3-256.7)$ & $56.9 \pm 17.6$ & $10(5-20)$ & $39.2 \pm 23.4$ \\
\hline 2001 & 817 & $36(7.6-83.3)$ & 106.9 (23.7-279.1) & $59.5 \pm 17.9$ & $10(0-20)$ & $38.7 \pm 19.4$ \\
\hline 2002 & 678 & $40.7(10-89.3)$ & 131.9 (32.2-300.7) & $60.2 \pm 19.6$ & $10(0-20)$ & $34.8 \pm 18.9$ \\
\hline 2003 & 661 & 35.8 (10.9-75.7) & $118.4(33.8-273.1)$ & $57.9 \pm 19.1$ & $10(0-20)$ & - \\
\hline 2004 & 607 & $40.6(7.8-89.4)$ & 118.2 (27.5-288.0) & $56.3 \pm 19.9$ & $10(0-20)$ & - \\
\hline 2005 & 599 & $39.8(10.4-88.6$ & 119.7 (30.9-279.0) & $55.3 \pm 18.0$ & $10(0-20)$ & - \\
\hline 2006 & 641 & $40(11.7-88.9)$ & 119.2 (31.9-261.2) & $51.0 \pm 17.9$ & $10(0-20)$ & - \\
\hline 2007 & 676 & $35.4(9.7-76)$ & $100.8(25.8-236.0)$ & $52.4 \pm 18.6$ & $5(0-10)$ & - \\
\hline $\begin{array}{l}\text { Rates of decrease } \\
\text { per year }\end{array}$ & & $1.5 \%$ & $1.6 \%$ & $0.4 \%$ & $5.5 \%$ & $2.2 \%$ \\
\hline
\end{tabular}

Abbreviations: IQR, interquartile range; M/ej, million per ejaculate; M/ml, million per millilitre; -, not available.

\section{Selected samples with a total normal sperm count}

In the group of selected samples with normal sperm count, the same trends of sperm quality deterioration with time were observed. Decreases in the mean sperm concentrations from 94.4 to 76.7 million $\mathrm{ml}^{-1}$, and in the mean total sperm count from 304.5 to 235.5 million were observed over the study period $\left(R^{2}=0.977, P<0.001\right.$ and $R^{2}=0.848, P<0.001$, respectively). These two parameters decreased by $1.0 \%$ and $1.3 \%$ per year respectively). The rapid motility declined over the study period from $31.1 \%$ to $10.7 \%\left(R^{2}=0.825, P<0.001\right.$, $5.2 \%$ per year). The mean percentage of sperm with normal morphology declined between 1988 and 2002 from $45.6 \%$ to $38.6 \%$ $\left(R^{2}=0.719, P=0.001,2 \%\right.$ per year $)$.

\section{DISCUSSION}

This report describes the results over a 20 -year precise analysis of sperm from 10932 patients. Over the course of the study, we adjusted for the patients' increased age, as we analysed the sperm parameters. In this population, we also separately analysed these semen samples with a total sperm count above 40 million.

\section{Sperm parameters decline in the male population consulting in our} centre

Over this period, we noted declining semen quality in the entire population as well as in selected men. Indeed, a significant decrease in both sperm concentration and total sperm count, and a severe decline of rapid progressive motility (grade a) were observed in the two populations. Comhaire et al. ${ }^{33}$ postulate that the percentage of spermatozoa with grade ' $a$ ' motility is the strongest indicator of the potential for in vivo fertilizing capacity of semen. Our results would suggest that an increasing proportion of men in our region could be candidates for assisted medical procreation techniques over time.

Detailed analysis of the sperm morphology showed significant increase of total sperm abnormalities (until 2002) and also of several of the functional regions of the spermatozoon, amorphous, multiple or tailless heads, multiple, headless or bent tails (Figure 2). Sperm morphology seems to be a very sensitive parameter of exposure to the toxicants. Any of them should lead to a temporary or permanent decrease in normal sperm morphology. As expected, semen parameters in the population with normal sperm count declined less severely than in the total population. This observation agrees with the conclusions of Oliva et al. ${ }^{34}$ which state that infertile patients constitute a highly susceptible group to environmental factors. It is also noteworthy that the number of men with a normal sperm count decreases over time, whereas we observe a concomitant increase of severe oligozoospermia and azoospermia in the population consulting our centre.

\section{Changes in laboratory staff or material could not explain the observations}

We analysed possible causes for our population's decline of sperm parameters and considered that these results would express a selection bias. Indeed, our patients constituted a population seeking couple's infertility treatment. Nevertheless, we showed that a decline of sperm parameters was also observed in patients with a normal sperm count. Our centre, since the outset, receives all men in infertile couples. We work with several physicians from Marseille and its region, who send us their patients for evaluation of male or couple infertility. Most of the men attending our centre have no knowledge of their sperm status during their first consultation. Although the evaluation of the percentage of motile spermatozoa and morphology is subjective, we emphasize that all our technicians have had the same training and the techniques of study remained constant. Since the opening of the laboratory, the strictest criteria have been applied. All semen samples wereanalysed according to standard methods, ${ }^{29-32}$ and efforts were made to keep the technique of semen analysis unchanged. Only the parameters which did not change over time were taken into account. Normal sperm morphology and bent tails were studied until the end of 2002. Indeed, Auger and Eustache classification, ${ }^{32}$ which was applied in our laboratory since 2003, introduced modifications of these two parameters. 

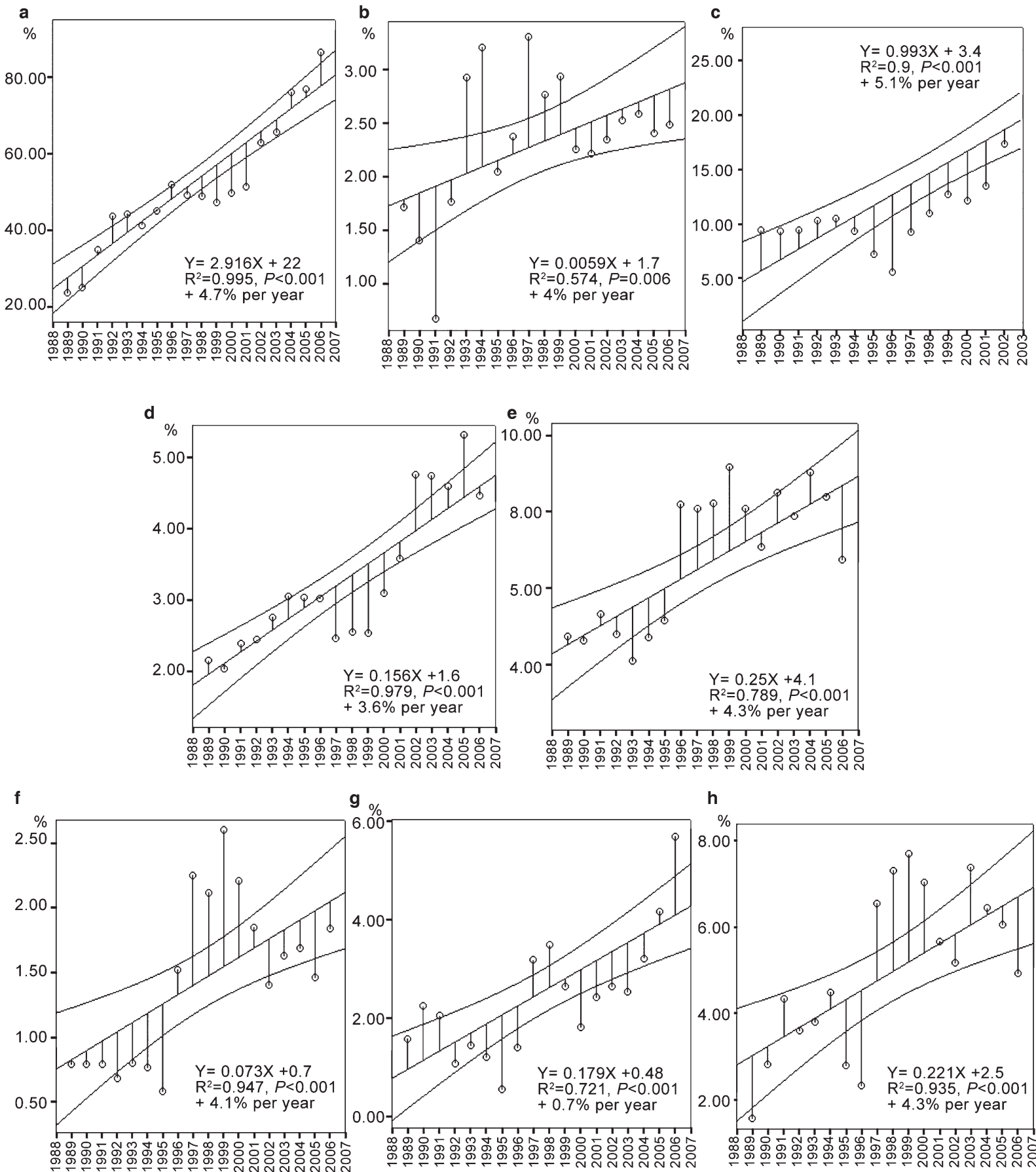

Figure 2 Linear regression lines of the mean per year of morphological abnormalities which change significantly over the study. For each parameter, the graph shows the linear regression line with 95\% confidence interval over the study period. For the percentage of spermatozoa with bent tail, results are showed until the end of 2002 : (a) amorphous head; (b) multiple head; (c) bent tail; (d) tailless head; (e) headless tail; (f) multiple tail; (g) thin head; (h) cytoplasmic droplet.

Moreover, it is important to note that technicians and physicians adhered to strict quality control (see MATERIALS AND METHODS). Although a new laminar flow hood and a second microscope for morphological sperm analysis were introduced, it does not explain the decline of sperm parameters. The quality of semen analysis remained a constant. Our goals remain dedicated to sperm analysis, research and statistical analysis of normal sperm parameters and sperm abnormalities.
Thus, the large sample size, the relatively stable population, the few changes in the laboratory staff and the very precise sperm analysis performed since the lab's inception are the main strengths of the present study. We also considered the advent of intracytoplasmic sperm injection (ICSI) during this study period. ICSI was introduced in 1995 in our centre and the curves did not show any drop of semen parameters during this period (Figure 1, Table 1). Moreover, the proportion of ICSI (45\%) has not varied in our centre since 1998, 
and those patients with severe male factors and actually benefiting from ICSI were before 1995 proposed for assisted reproductive technology with sperm donor.

\section{Contribution of environmental factors}

During the study, there was an increase of leucocytes and $\mathrm{pH}$, and infection may be a contributing factor to explain our observations. ${ }^{35}$ Nevertheless, our results appear to be in keeping with the hypothesis advanced by Sharpe and Skakkebaek; ${ }^{36}$ that is, environmental factors during foetal, childhood/pubertal period or adult life, can have detrimental effects on spermatogenesis. The higher risk of testicular cancer and poor semen quality over the past decades has drawn attention to the possibility that environmental xenoestrogens may be implicated. ${ }^{37-39}$ Among xenoestrogens, phthalates are ubiquitous in human life. Hsu et al. ${ }^{40}$ and Han et al. ${ }^{41}$ reported that polycyclic aromatic hydrocarbons are associated with DNA damages. Recent studies have demonstrated that not only androgens but also oestrogens have an important role in male reproduction. Their activity is mediated by androgen receptors and oestrogen receptors $(\mathrm{ER} \alpha$ and $\mathrm{ER} \beta)$ present on spermatozoa. ${ }^{25-27}$ The conversion of androgens into oestrogens is catalysed by cytochrome $\mathrm{P} 450$ aromatase (P450 arom) present in Leydig cells, elongated spermatids and spermatozoa. ${ }^{42,43}$ Many endocrine disrupting compounds are chemicals with oestrogenic or anti-androgenic activity. They modify the synthesis or action of testosterone or estrogens, or interfere with their respective hormone receptors. They also promote receptor degradation. Some toxic as Atrazine appears to interact strongly with a novel functional oestrogen transmembrane receptor, the $\mathrm{G}$ protein-coupled receptor 30 which is overexpressed in postpubertal germ cell tumours. ${ }^{44,45}$

Other pathogenic processes could lead to spermatogenic defects. Environmental factors may either damage critical genes or alter gene expression by interfering with the epigenetic programming. ${ }^{46}$ The genetic damages may also be revealed by the increasing frequency of meiotic abnormalities in fertile men in recent decades ${ }^{47}$ or by models of germ cell cultures with toxic presence. Meiosis is thus shown to be severely impaired by low concentrations of hexavalent chromium. ${ }^{48}$ Consequently, the increasing concentration of heavy metals due to rise of vehicular pollution can also impair spermatogenesis. Moreover, high frequencies of diploidy and disomy were associated with environmental exposure and lifestyle habits. ${ }^{49}$

It is important to emphasize the marked geographical differences in the last secular trend in male reproductive function. ${ }^{50-52}$ The explanation for this regional trend is not known. Giwercman and LundgergGiwercman ${ }^{46}$ argue that the population may genetically differ, but that probably environmental or life style related factors are operating. Thus, decline of sperm parameters in our study's population could result, to a great extent, from the numerous toxicants of our heavily industrialized region.

\section{CONCLUSION}

Our results clearly indicate that the semen quality in the population of men consulting for couple infertility decreased in the region of Marseille from 1988 to 2007. As many authors suggest, we also believe that environmental factors have detrimental effects on spermatogenesis and therefore following regional trends of semen quality are required. Semen analysis is a non-invasive method, and, although it is generally admitted that semen parameters are poor indicators of fertility potential, abnormal semen analysis suggests that the probability of achieving fertility is lower than normal. ${ }^{53-55}$ We would like to draw particular attention to the trend of the sperm count curve over time. Presently the decline is linear, but a break in the straight line, if occurring, could predict a severe and alarming defect of the reproductive function.

\section{AUTHOR CONTRIBUTIONS}

CGS made substantial contributions to data acquisition, analysis and interpretation. ADL provided the epidemiologic and statistical analysis. FR carried out the computerization of the sperm parameters in the hospital. VA performed the biological patient advices for most of this study. BC realized the clinical patient advices during the bulk of this study. MHP participated in the design of the study and helped to draft the manuscript. PD provided critical review of the manuscript. MRG conceived the study and drafted the manuscript.

\section{COMPETING FINANCIAL INTERESTS}

The authors declare no competing financial interests.

\section{ACKNOWLEDGMENTS}

The authors would like to thank the laboratory's two successive department heads, Professor J. M. Luciani who initiated the computerization of the data and Professor J. M. Grillo; the directors of the 'Centre de Procréation Médicalement Assistée de Marseille' (CPMA), Professor R. Erny and Professor M. Gamerre, the two successive directors of the Centre of Assisted Reproductive Technique of Marseille. We are grateful to Dr J. C. Reynier for its legal assistance, and to the technicians of the laboratory of spermiology, C. Metton, M. J. Fays-Bernardin and D. Daioglou, for their technical assistance. We also thank all the physicians of the CPMA and of the Department of Urology, the physicians of Marseille and its region which send us their patients for sperm analysis, and the rotating staff of interns who have worked in the laboratory of sperm analysis.

1 Carlsen E, Giwercman A, Keiding N, Skakkebaek NE. Evidence for decreasing quality of semen during past 50 years. BMJ 1992; 305: 609-13.

2 Auger J, Kunstmann JM, Czyglik F, Jouannet P. Decline in semen quality among fertile men in Paris during the past 20 years. N Engl J Med 1995; 332: 281-5.

3 Adamopoulos DA, Pappa A, Nicopoulou S, Andreou E, Karamertzansi M et al. Semina volume and total sperm number trends in men attending subfertility clinics in the Greater Athens area during the period 1977-1993. Hum Reprod 1996; 11: 193641.

4 van Waeleghem K, de Clercq N, Vermeulen L, Schoonjans F, Comhaire F. Deterioration of sperm quality in young healthy Belgian men. Hum Reprod 1996; 11: 325-9.

5 Lackner J, Schatzl G, Waldhor T, Resch K, Kratzik C et al. Constant decline in sperm concentration in infertile males in an urban population: experience over 18 years. Fert Steril 2005; 84: 1657-61.

6 Spirada S, Fonseca S, Lee A, Harrild K, Giannaris D et al. Trends in semen parameters in the northeast of Scotland. J Androl 2007; 28: 313-9.

7 Shine R, Peek J, Birdsall M. Declining sperm quality in New Zealand over 20 years. NZ Med J 2008; 121: 50-6.

8 Mukhopadhyay D, Varghese A, Pal M, Banerjee S, Bhattacharyya A et al. Semen quality and age-specific changes: a study between two decades on 3729 male partners of couples with normal sperm count and attending an andrology laboratory for infertility-related problems in an Indian city. Fert Steril 2010; 93: 2247-54.

9 Bujan L, Mansat A, Pontonnier F, Mieusset R. Time series analysis of sperm concentration in fertile men in Toulouse between 1977 and 1992. BMJ 1996; 312: 471-2

10 Berling S, Wölner-Hanssen P. No evidence of deteriorating semen quality among men in infertile relationships during the last decade: a study of males from Southern Sweden. Hum Reprod 1997; 12: 1002-5.

11 Rasmussen PE, Erb K, Westergaard LG, Laursen SB. No evidence for decreasing semen quality in four birth cohorts of 1055 Danish men born between 1950 and 1970. Fert Steril 1997; 68: 1059-64.

12 Emanuel E, Gobuloff E, Fisch H. MacLeod revisited: sperm counts distributions in 374 fertile men from 1971 to 1994. Urology 1998; 51: 86-8.

13 Seo JT, Rha K, Park YS, Lee MS. Semen quality over a 10 year period in 22249 men in Korea. Int J Androl 2000; 3: 194-8.

14 Itoh N, Kayama F, Tatsuki J, Tsukamoto T. Have sperm counts deteriorated over the past 20 years in healthy young Japanese men? Results from the Sapporo area. J Androl $2001 ; 22: 40-4$ 
15 Costello MF, Sjoblom P, Haddad Y, Steigrad SJ, Bosch EG. No decline in semen quality among potential sperm donors in Sydney, Australia, between 1983 and 2001. J Assist Reprod Genet 2002; 19: 284-90.

16 Marimuthu P, Kapilashrami MC, Misro MM, Singh G. Evaluation of trend in semen analysis for 11 years in subjects attending a fertility clinic in India. Asian J Androl 2003; 5: 221-5.

17 te Velde E, Burdof A, Nieschlag E, Eijkemens R, Kremer JA et al. Is human fecundity declinig in Western countries? Human Reprod 2010; 25: 1348-53.

18 Jensen TK, Sobotka T, Hansen MA, Pedersen AT, Lutz W et al. Declining trends in conception rates in recent birth cohorts of native Danish women: a possible role of deteriorating male reproductive health. Int J Androl 2008; 31: 81-92.

19 Joensen UN, Skakkebaek N, Jorgensen N. Is there a problem with male reproduction? Nat Clin Endo Metab 2009; 5: 144-5.

20 Paulsen CA, Berman NG, Wang C. Data from men in greater Seattle area reveals no downward trend in semen quality: further evidence that deterioration of semen quality is not geographically uniform. Fert Steril 1996; 65: 1015-20.

21 Lipshultz $\mathrm{L}$. The debate continues»-the continuing debate over the possible decline in semen quality. Fert Steril 1996; 65: 909-11.

22 Jorgensen N, Andersen AG, Eustache F, Irvine S, Suominen J et al. Regional differences in semen quality in Europe. Hum Reprod 2001; 16: 1012-9.

23 Svechnikov K, Izzo G, Landreh L, Weisser J, Söder O. Endocrine disruptor and Leydig cell function. J Biomed Biotechnol 2010; 2010: pii 684504.

24 Fisher JS. Environmental anti-androgens and male reproductive health: focus on phthalates and testicular dysgenesis syndrome. Reproduction 2004; 27; 305-15.

25 Aquila S, Sisci D, Gentile M, Middea E, Catalano S et al. Estrogen receptor ER $\alpha$ and $E R \beta$ are both expressed in human ejaculated spermatozoa: evidence of their direct interaction with phosphatidylinositol-3-OH kinase/Akt pathway. J Clin Endocrinol Metab 2004; 89: 1443-51.

26 Aquila S, Liddea E, Catalano S, Marsico S, Lanzino M et al. Human sperm express a functional androgen receptor: effects on PI3K/AKT pathway. Hum Reprod 2007; 22 2594-605

27 Solakidi S, Psarra AMG, Nikolaropoulos S, Sekeris CE. Estrogen receptor $\alpha$ and $\beta$ (ER $\alpha$ and $E R \beta$ ) and androgen receptor (AR) in the human sperm: localization of $E R \beta$ and $A R$ in mitochondria of the midpiece. Hum Reprod 2005; 20: 3481-7.

28 Cooper TG, Noonan E, von Eckardstein S, Auger J, Baker HW et al. World Health Organization reference values for human semen characteristics. Hum Reprod Update 2010; 16: 231-45.

29 World Health Organization. WHO Laboratory Manual for the Examination of Human Semen and Sperm-Cervical Mucus Interaction. Cambridge: Cambridge University Press; 1987. p1992.

30 World Health Organization. WHO Laboratory Manual for the Examination and Processing of Human Semen, 5th ed. Geneva: World Health Organization; 2010.

31 David G, Bisson JP, Czyglik F, Jouannet P, Gernigon C. Anomalies morphologiques du spermatozoïde humain. Propositions pour un système de classification. $J$ Gynecol Obstet Biol Reprod 1975; 4: 17-36.

32 Auger J, Eustache F. Standardisation de la classification morphologique des spermatozoïdes humains selon la méthode de David modifiée. Andrologie 2000; 10: 358-73.

33 Comhaire FH, Vermeulen L, Schoonjans F. Reassessment of the accuracy of traditional sperm characteristics and adenosine triphosphate (ATP) in estimating the fertilizing potential of human semen in vivo. Int JAndrol 1987; 10: 653-62.

34 Oliva A, Spira A, Multigner L. Contribution of environmental factors to the risks of male infertility. Hum Reprod 2001; 16: 1768-76.
35 Feki NC, Abid N, Rebai A, Sellami A, Ayed BB et al. Semen quality decline among men in infertile relationships: experience over 12 years in the south of Tunisia. $J$ Androl 2009; 30: 541-7

36 Sharpe RM, Skakkebaek NE. Are oestrogens involved in falling sperm counts and disorders of the male reproductive tract? Lancet 1993; 341: 1392-5.

37 Irvine S, Cawood C, Richardson D, MacDonald E, Aitken J. Evidence of deteriorating semen quality in the United Kingdom: birth cohort study in men in Scotland over 11 years. BMJ 1996; 312: 467-71.

38 Eertmans F, Dhooge W, Stuyvaert S, Comhaire F. Endocrine disruptors: effects on male fertility and screening tools for their assessment. Tox in Vitro 2003; 17: 515-24.

39 Burns WR, Sabanegh E, Dada R, Rein B, Agarwal A. Is male infertility a forerunner to cancer? Int Braz J Urol 2010; 36: 527-36.

40 Hsu PC, Chen IY, Wu KY, Pan MH, Chen JR et al. Sperm DNA damage correlates with polycyclic aromatic hydrocarbons biomarker in coke-oven workers. Int Arch Occup Environ Health 2006; 79: 349-56.

41 Han X, Zhou N, Cui Z, Li L, Cai M et al. Association between urinary polycyclic aromatic hydrocarbon metabolites and sperm DNA damage: a population study in Chongqing, China. Environ Health Persp 2011; 119: 652-7.

42 Lambard S, Galeraud-Denis I, Bouraima H, Bourguiba S, Chocat A et al. Expression of aromatase in Human ejaculated spermatozoa: a putative marker of motility. Mol Hum Reprod 2003; 9: 117-24.

43 Aquila S, Sisci D, Gentile M, Middea E, Siciliano L et al. Human ejaculated spermatozoa contain active P450 Aromatase. J Clin Endocrinol Metab 2002; 87: 3385-90.

44 Franco R, Boscia F, Gigantino V, Marra L, Esposito F et al. GPR30 is over expressed in post-pubertal testicular germ cell tumors. Cancer Biol Ther 2011; 15: 609-13.

45 Jowa L, Howd R. Should atrazine and related chlorotriazines be considered carcinogenic for human health risk assessment. J Environ Sci Health C Environ Carcinog Ecotoxicol Rev 2011; 29: 91-144.

46 Giwercman A, Lundberg-Giwercman Y. Environmental factors and testicular function. Best Pract Res Clin Endocrinol Metab 2011; 25: 391-402.

47 Uroz L, Rajmil O, Templado C. Meiotic chromosomes abnormalities in fertile men are they increasing? Fert Steril 2011; 95: 141-6.

48 Geoffoy-Siraudin C, Perrard MH, Chaspoul F, Lanteaume A, Gallice P et al. Validation of a rat seminiferous tubule culture model as a suitable system for studying toxicant impact on meiosis effect of hexavalent chromium. Tox Sci 2010; 116: 286-96.

49 Pacchierotti F, Adler ID, Eichenlaub-Ritter U, Mailhes JB. Gender effects on the incidence of aneuploidy in mammalian germ cells. Environ Res 2007; 104: 46-69.

50 Toppari J, Virtanen HE, main KM, Skakkebaek NE. Cryptorchidism and hypospadias as a sign of testicular dysgenesis syndrome (TDS): environmental connection. Birth Defects Res A Clin Mol Teratol 2010; 88: 910-9.

51 Fish H, Goluboff ET. Geographic variations in sperm counts: a potential cause of bias in studies of semen quality. Fertil Steril 1996; 5: 1044-6.

52 Jorgensen N, Andersen AG, Eustache F, Irvine DS, Suominen J et al. Regional differences in semen quality in Europe. Hum Reprod 2001; 16: 1012-9.

53 Jouannet P, Ducot B, Feneux D, Spira A. Male factors and the likelihood of pregnancy in infertile couples. I. Study of sperm characteristics. Int J Androl 1988; 11:379-94.

54 Bonde JP, Ernst E, Jensen TK, Hjolund NH, Kolstad H et al. Relation between semen quality and fertility. A population based study of 430 first-pregnancy planners. Lancet 1998; 352: 1172-7.

55 Skakkebaek NE. Normal references ranges for semen quality and their relations to fecundity. Asian J Androl 2010; 12: 95-8. 